\title{
Evaluación de Parámetros de Rugosidad usando Análisis de Imágenes de Diferentes Microscopios Ópticos y Electrónicos
}

\author{
Marcelo L. Alves ${ }^{(1,3)}$, Bruno B. Ferreira ${ }^{(2)}$ y Fabiana R. Leta ${ }^{(3)}$ \\ (1) Instituto Nacional de Metrologia, Normalização e Qualidade Industrial - Inmetro, \\ Rio de Janeiro-Brasil (e-mail: malves@inmetro.gov.br; particular.limaalves@gmail.com) \\ (2) Universidade Federal do Rio de Janeiro, Programa de Pós-Graduação em Informática, Rio de \\ Janeiro-Brasil (e-mail: tinnus@gmail.com) \\ (3) Universidade Federal Fluminense, Programa de Pós-Graduação em Engenharia Mecânica, \\ Niterói, Rio de Janeiro-Brasil (e-mail: fabiana@ic.uff.br)
}

Recibido Nov. 04, 2010; Aceptado Dic. 06, 2010; Versión Final recibida Ene. 19, 2011

\section{Resumen}

Se presenta una metodología para análisis de la rugosidad basada en las características superficiales de las imágenes obtenidas de microscopios ópticos y electrónicos. Se muestra un método de análisis basado en las características de rugosidad de textura. Las características que describen las texturas y que se utilizan para clasificarlas, provienen de los descriptores Haralick, que también se basan en matrices de co-ocurrencia. Los patrones de rugosidad primaria son evaluados y clasificados de acuerdo con varias características que utilizan los valores de estos descriptores. Los valores extraídos de los patrones se incorporan después a una red neuronal artificial de perceptrón multicapa. Se concluye que es posible iniciar la implementación del control de piezas metálicas para inspección de la calidad industrial de productos manufacturados a partir de ese sistema de reconocimiento de la rugosidad.

Palabras clave: rugosidad, textura, redes neuronales, reconocimiento de patrones

\section{Evaluation of Roughness Parameters using Image Analysis from Different Optical and Electronic Microscopes}

\begin{abstract}
A methodology for analyzing the roughness based on surface characteristics of the images obtained from optical and electronic microscopes, is presented. The features that describe textures and are also used to classify them derive from the Haralick descriptors, which are based on cooccurrence matrices. The primary roughness patterns are evaluated and classified according to several features which use the values of these descriptors. The values extracted from the patterns are fed to artificial neural network of the multi-layer perceptron type. It is concluded that it is possible to start implementing the control of metal parts for industrial quality control of manufactured products through this system of roughness recognition.
\end{abstract}

Keywords: roughness, textural descriptors, neural networks, pattern recognition 


\section{INTRODUCCIÓN}

La rugosidad consiste en pequeñas irregularidades presentes en la superficie. Estas irregularidades caracterizan el acabado o textura de la superficie, que puede ser definida como un conjunto de patrones existentes en las superficies físicas. De esta manera, para que se pueda definir el concepto que involucra la superficie rugosa, es importante comprender sus principales parámetros. Las irregularidades de la superficie comprenden dos grupos de errores, los macrogeométricos y los micro-geométricos. Los errores macro-geométricos son errores de forma verificables por medio de instrumentos convencionales de medición, como micrómetros, relojes comparadores, y proyectores de perfil. Entre esos errores, se incluyen divergencias de ondulaciones, ovalización, rectilinidad, planicidad, circularidad, etc. El otro grupo de errores corresponde a los errores micro-geométricos, que son los errores conocidos como rugosidad.

Existen una serie de métodos para la medición de la rugosidad los cuales pueden ser separados en dos grupos: de contacto y sin contacto. En (Vorburger, et al, 2007) se muestra una comparación entre los métodos de contacto (más tradicionales) y los métodos de no contacto. $A$ partir de la evolución tecnológica, los métodos de no contacto fueron el fruto de mucha investigación. Como ejemplo, pueden ser citados los métodos ópticos presentados en (Hocken, et al, 2005) y la medición por interferometría presentada en (Rhee, et al 2005 y Harasaki, et al 2000).

Existen también métodos de visión computacional para el control de fabricación de piezas que captan la imagen de la superficie para controlar las herramientas de corte y mejorar la calidad de la fabricación. Estos métodos básicamente son programas de computador que permiten controlar parámetros de corte basados en el análisis de la rugosidad superficial. En (Reddy y Rao, 2005), se mostró un modelo empírico de rugosidad superficial para el modelo final del acero de carbón medio, cuyos parámetros fueron optimizados utilizando un algoritmo genético. En (Oktem, et al, 2005), se determinaron las mejores condiciones de corte para una dada rugosidad de la superficie durante el proceso de fabricación. La rugosidad de la superficie fue modelada con base en la respuesta dada por el método que optimizó las condiciones de corte. En (Prakasvudhisarn, et al., 2009) fue propuesto un abordaje para la determinación de la condición ideal de corte para una rugosidad superficial deseada durante el proceso de fresado. La metodología propuesta consiste en dos partes: (a) modelaje de la rugosidad y (b) selección óptima de parámetros de corte.

Como existe una amplia gama de métodos que fueron desarrollados para medir la textura superficial, la Organización Internacional de Normas (ISO), en el Comité Técnico 213, que trata de la verificación dimensional del producto y especificaciones geométricas, creó un grupo de trabajo para discutir la normalización de la medición de textura en 3D (ISO 25178-6, 2010), como también la revisión de las normas existentes sobre medición tradicional de rugosidad en 2D (ISO 4287, 1997). La evaluación de rugosidad de superficies viene siendo objeto de estudio en las más diversas áreas del conocimiento. En el área de la ingeniería, los campos de mayor interés se refieren a procesos de manufactura y tribología (Bongaerts et al, 2007; Ozcelik y Bayramoglu, 2006; Zain, et al, 2010). Adicionalmente, el análisis de rugosidad se constituye como una área de investigación importante con aplicaciones en bibliotecas digitales, bancos de datos multimedia, imágenes médicas, robótica, detección remota y control de la calidad, entre otras (Bashar, et al, 2003). Por ejemplo, la textura puede ser definida como un "patrón estadístico local de texturas primitivas en el dominio de observación de interés" (Sengur et al., 2007), siendo por lo tanto, frecuentemente usada como un descriptor regional de imágenes. La extracción de características de textura se basa en modelos matemáticos que pueden involucrar matrices de co-ocurrencia de nivel-gris, funciones de auto-correlación, campos aleatorios de máxima entropía (Yang y Liu, 2002), filtros de Gabor y Wavelets entre otros.

La extracción de características usando abordaje estadístico propicia la descripción de imágenes a través de reglas que gobiernan la distribución y la relación entre los diferentes niveles de gris (Varma y Zisserman, 2005). Innumerables medidas pueden ser extraídas de la distribución de los niveles de gris en imágenes, entre las cuales se pueden citar: media, varianza, desviación estándar, energía y entropía, entre otras. El abordaje estadístico puede ser dividido en dos vertientes, la de primer orden, en la cual se extraen características a partir de histogramas 
(Ginneken y Romeny, 2003; Paschos y Petrou, 2003) de primer orden y, la de segundo orden, que tiene en cuenta el posicionamiento relativo de la ocurrencia de los niveles de gris.

En este artículo se presenta una metodología que pretende obtener parámetros de rugosidad de superficies a partir de análisis de sus características texturales. Se utiliza el abordaje de segundo orden para obtener estas características, que también es explorado en (Alegre et al, 2010). Las matrices de co-ocurrencia forman la base para elaborar diversas medidas estadísticas conocidas como descriptores de Haralick (Haralick, 1973). En este trabajo se utilizaron, 8 descriptores: Segundo Momento Angular (SMA), Contraste, Homogeneidad, Probabilidad Máxima, Entropía, Momento de Diferencias de Orden $k$, Momento Inverso de Diferencias de Orden $k$, Energía o Uniformidad, Varianza o Contraste y Varianza Inversa.

Finalmente, redes neuronales artificiales han sido ampliamente utilizadas en aplicaciones relativas a la clasificación y recuperación de imágenes (Markou y Singh, 2003). El uso de los modelos neuronales para estas aplicaciones está directamente relacionado con sus principales características. Se citan la capacidad de aprender y de generalizar la información aprendida. Otra característica importante de las redes neuronales es la capacidad de auto-organización, en que la red atribuye un patrón de entrada a una clase entre un conjunto de clases conocidas. El procedimiento empleado en el aprendizaje de una red neuronal es denominado algoritmo de entrenamiento y su función principal es la modificación de los pesos sinápticos con la finalidad de alcanzar el objetivo (Haralick, 1979). En este artículo se utiliza el modelo Perceptrón multi-capas para la obtención de los parámetros de rugosidad a partir de las características de textura obtenidas en imágenes digitales de patrones de rugosidad. Para validar esta investigación se torna importante utilizar patrones de rugosidad que puedan ser comparados con los resultados obtenidos. De esta forma, las imágenes utilizadas se refieren a patrones primarios de rugosidad aperiódicos metálicos, propiedad del Instituto Nacional de Metrología, Normalización y Calidad Industrial - Inmetro, cuyo fabricante es el PTB-Rauhnormal-Halle.

Los patrones poseen las siguientes características:

1-Rugosidad Fina $\left(674-1-R_{a}=0,178 \mu \mathrm{m}, R_{z}=1,52 \mu \mathrm{m}, R_{\max }=1,81 \mu \mathrm{m}, \lambda_{c}=0,8 \mathrm{~mm}\right.$.

2-Rugosidad Media (559-2) - $R_{a}=0,61 \mu \mathrm{m}, R_{z}=3,35 \mu \mathrm{m}, R_{\max }=4,05 \mu \mathrm{m}, \lambda_{c}=0,8 \mathrm{~mm}$.

3-Rugosidad Alta $-549-3 R_{a}=1,77 \mu \mathrm{m}, R_{z}=8,9 \mu \mathrm{m}, R_{\max }=10,2 \mu \mathrm{m}, \lambda_{c}=0,8 \mathrm{~mm}$.

La metodología adoptada consiste en la realización de las siguientes etapas: 1- Definición de los patrones de rugosidad a ser evaluados, como descrito en el párrafo anterior; 2- Adquisición de imágenes de muestras de rugosidad; 3- Extracción de características de textura; 4- Modelaje y Entrenamiento de redes neuronales artificiales; y 5- Definición de la rugosidad a partir de la red neuronal artificial. Este artículo describe las últimas cuatro etapas en las siguientes secciones.

\section{ADQUISICIÓN DE IMÁGENES}

La forma como se efectúa la adquisición de la imagen es fundamental para el suceso del trabajo en cuestión.

\section{Microscopio óptico}

Las imágenes fueron adquiridas en tonos gris en un microscopio óptico (Olympus BX51M).

Las imágenes de las muestras fueron registradas con aumentos de 50, 100 e 200 veces para cada patrón de rugosidad. La Tabla 1 presenta las imágenes de los tres patrones de rugosidad obtenidas en aumentos distintos.

\section{Microscopio electrónico}

Las imágenes, también, fueron adquiridas en tonos gris usando un microscopio electrónico (EI Microscopio Electrónico de Barrido (MEV)) con aumento máximo de 10000 veces, fueron producidas imágenes con aumentos de 100, 500, 1000 e 2500 veces para cada patrón de rugosidad. La tabla 2 presenta las imágenes de los tres patrones de rugosidad obtenidas en aumentos distintos. 
Tabla 1: Imágenes de los patrones de rugosidad alta, media y fina.( Microscopio óptico)

\begin{tabular}{|c|c|c|c|}
\hline & $50 x$ de $500 \mu \mathrm{m}$ & $100 x$ de $200 \mu \mathrm{m}$ & $200 x$ de $100 \mu \mathrm{m}$ \\
\hline $549-3$ & 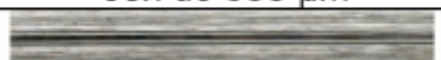 & (n) & (n) \\
\hline Rugosidad & 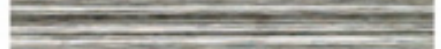 & 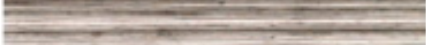 & Denturis \\
\hline & Den & 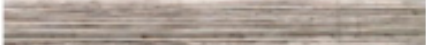 & $7=$ \\
\hline & 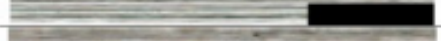 & $=$ & \\
\hline Rugosidad & $=$ & 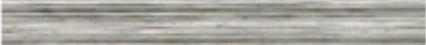 & $=$ \\
\hline Media & -2 & 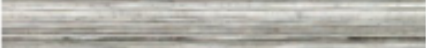 & \\
\hline 6741 & & & \\
\hline Rugosidad & & & $\overline{\bar{\nu}}$ \\
\hline Fina & & & \\
\hline & $=$ & & $=$ \\
\hline
\end{tabular}

Tabla 2: Imágenes de los patrones de rugosidad alta, media y fina. (Microscopio Electrónico)

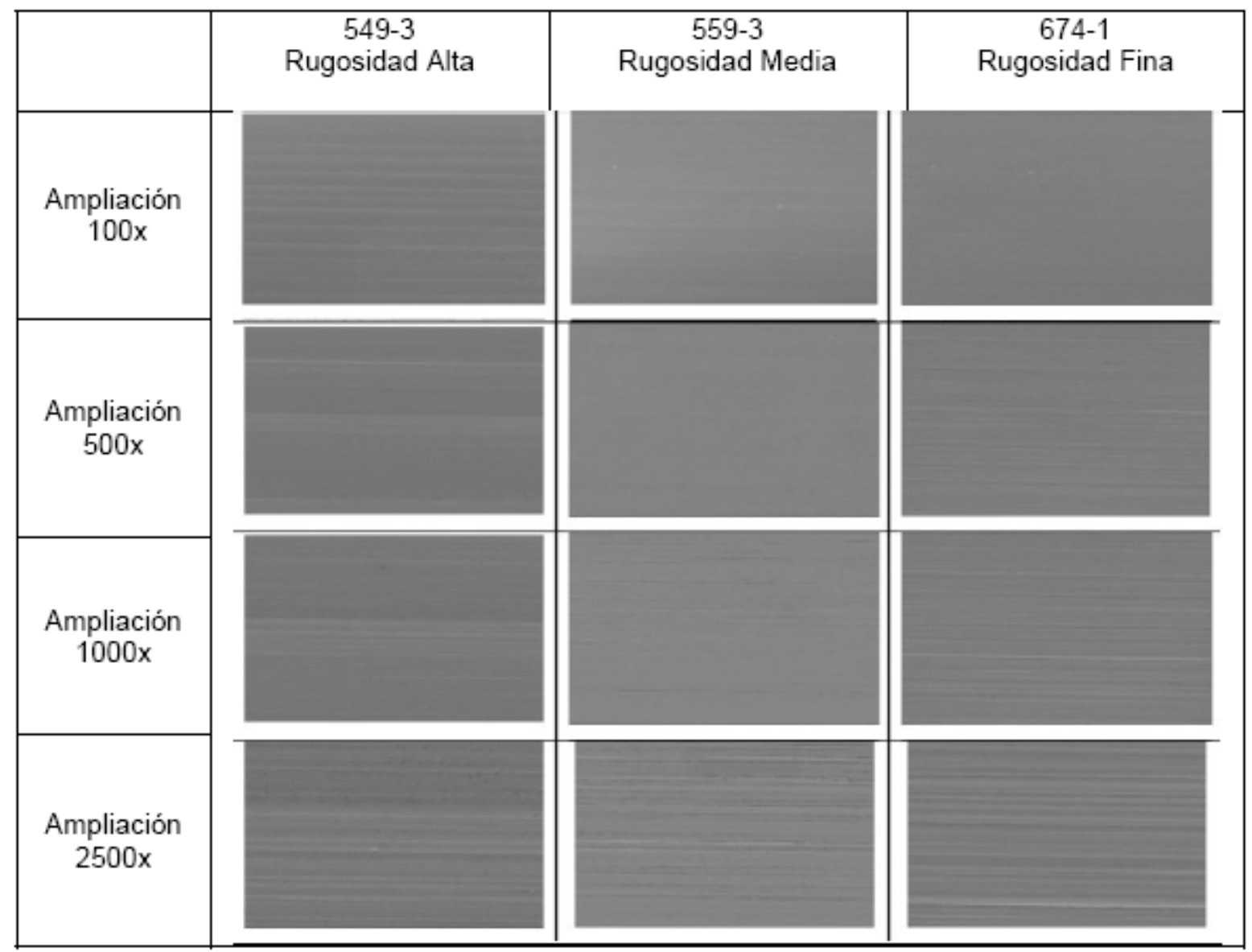

\section{EXTRACCIÓN DE CARACTERÍSTICAS DE TEXTURA}

La textura puede ser definida como un conjunto de determinados patrones existentes en las superficies físicas, perceptibles al ojo humano y que traen gran cantidad de informaciones sobre la naturaleza de la superficie, como suavidad, rugosidad y regularidad. Para caracterizar la textura en una imagen, se utilizan descriptores de Haralick que definen la forma de distribución de las diferentes intensidades de tonos en la imagen. Ejemplos de descriptores de textura son: Segundo Momento Angular (SMA), Contraste, Homogeneidad, Probabilidad Máxima, Entropía, Momento de 
Diferencias de Orden k, Momento Inverso de Diferencias de Orden k, Energía o Uniformidad, Varianza o Contraste, Varianza Inversa. Las definiciones de esos descriptores son presentadas a continuación, siendo $p(i, j)$ la intensidad del tono de gris de la imagen en la coordenada $i, j$ y considerando que tiene que ser asociada a un ángulo $\theta$ y a una distancia $d$, formando $(d, \theta)$.

Homogeneidad $(d, \theta)$

Descripción: Distribución de pixeles.

$\mathrm{H}=\sum_{i} \sum_{j} \frac{p(i, j)}{(1+|i-j|)}$

\section{Probabilidad Máxima $(d, \theta)$}

Descripción: Indica la dirección más importante de la textura a ser examinada.

$\mathrm{MP}=\max _{i, j} p(i, j)$

Entropía $(d, \theta)$

Descripción: Mide la información contenida en $p$, muchos valores nulos representan poca información.

$\mathrm{E}=-\sum_{i} \sum_{j} p(i, j) \log p(i, j)$

Momento de diferencias orden $k(d, \theta)$

Descripción: Distorsión de la imagen. Este descriptor presenta valores bajos, si $p$ tiene valores mayores en la diagonal principal.

$\mathrm{MD}=\sum_{i} \sum_{j}(i-j)^{k} p(i, j)$

Momento inverso de diferencias de orden $k(d, \theta)$

Descripción: Inverso de contraste. Este descriptor presenta valores mayores si $p$ tiene valores pequeños en la diagonal principal.

$\mathrm{M}=\sum_{i} \sum_{j} \frac{p(i, j)}{(i-j)^{k}}$

\section{Energía o Uniformidad $(d, \theta)$}

Descripción: Retorna la suma de los elementos elevados al cuadrado dentro de la matriz de coocurrencia de tonos de gris.

Faja de valores posibles: 0 a 1. La energía posee valor 1 para una imagen constante (mismo tono gris en toda su extensión).

$\mathrm{E}_{\mathrm{N}}=\sum_{i} \sum_{j} p^{2}(i, j)$

\section{Varianza o Contraste $(d, \theta)$}

Descripción: Retorna una medida del contraste entre las intensidades de un pixel analizado y del pixel vecino. La comparación es realizada en todos los pixeles de la imagen. Para una imagen constante (mismo tono de gris en toda la extensión), el contraste es 0 (cero). El contraste de la imagen corresponde al Momento de orden 2. 
$V=\sum_{i} \sum_{j}(i-j)^{2} p(i, j)$

\section{Varianza Inversa $(d, \theta)$}

Descripción: Inverso de contraste.

$\mathrm{IV}=\sum_{i} \sum_{j} \frac{p(i, j)}{(i-j)^{2}}, i \neq j$

\section{Descripción de texturas por matriz de co-ocurrencia}

El abordaje estadístico para la caracterización de texturas puede ser dividido en dos importantes vertientes: (a) primer orden, en el cual se extraen características a partir de histogramas de primer orden y (b) segundo orden, que tiene en cuenta la posición relativa de la ocurrencia de los niveles de gris. En (Haralick 1979), fue propuesta una metodología para descripción de texturas basada en estadística de segundo orden, donde son definidas características provenientes del cálculo de matrices denominadas "matrices de co-ocurrencia". Estas matrices se basan en el recuento del número de combinaciones diferentes de niveles de gris que ocurren en una imagen, en una determinada dirección. Para la obtención de tales matrices, se considera la variación de la distancia y dirección $(d, \theta)$, entre pixeles vecinos. Fueron utilizadas cuatro direcciones: $0^{\circ}, 45^{\circ}, 90^{\circ}$ y $135^{\circ}$, presentado en la Fig. 1.

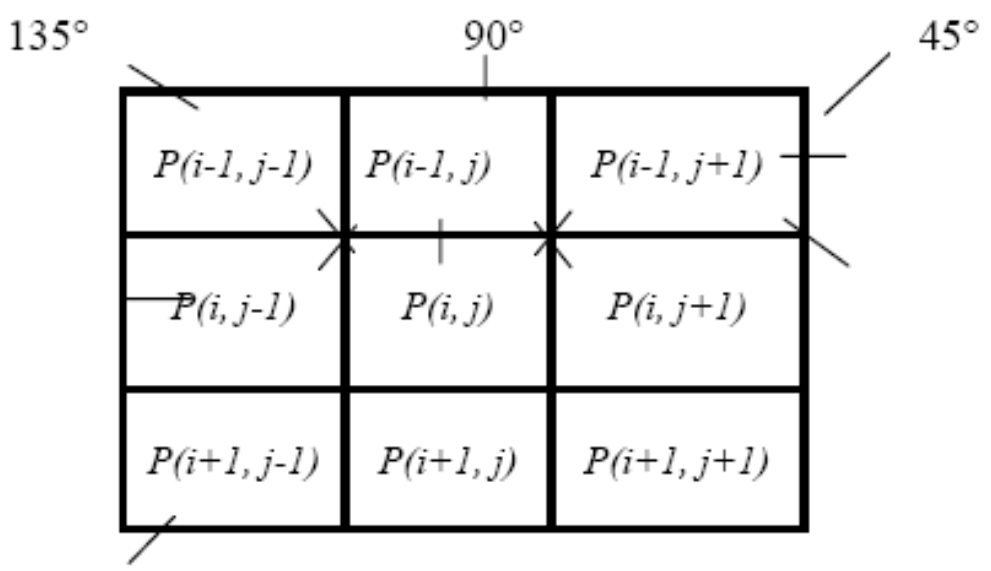

Fig.1: Direcciones y distancias de la matriz de co-ocurrencia.

Para cada dirección y cada distancia, se elabora una matriz de co-ocurrencia. Como ejemplo, se presenta a continuación, la imagen representada por la matriz $n$ de puntos Fig. 2a. Para la dirección de $0^{\circ}$ y la distancia 1 , se tiene una matriz de co-ocurrencia presentada en la Fig. $2 \mathrm{~b}$ La matriz sufre un proceso de reducción, dividiéndose cada elemento por el número máximo de elementos en cada posición.

\begin{tabular}{|c|c|c|}
\hline 8 & 8 & 2 \\
\hline 8 & 6 & 2 \\
\hline 2 & 2 & 2 \\
\hline
\end{tabular}

(2a)

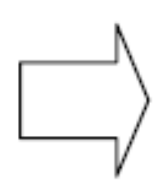

\begin{tabular}{|l|l|l|l|l|}
\hline 0 & 0 & 0 & 1 & 2 \\
\hline 1 & 1 & 0 & 1 & 1 \\
\hline 2 & 2 & 1 & 0 & 0 \\
\hline 1 & 1 & 0 & 2 & 0 \\
\hline 0 & 0 & 1 & 0 & 2 \\
\hline
\end{tabular}

$(2 b)$

Fig.2a: Matriz de co-ocurrencia $\mathrm{P}$ de la imagen, dirección de $0^{\circ}$ y a distancia 1 . El valor $P(i, j)$ almacenado en una línea $i$ y columna $j$ consiste en el número de ocurrencias de pixeles de valor $j$ a la izquierda o a la derecha y una distancia de 1 pixel. Fig.2b: Ejemplo de imagen con niveles de gris 0,1 y 2 . 
El problema consiste en analizar un conjunto de matrices de co-ocurrencia para caracterizar la textura a que se refieren. Las matrices de co-ocurrencia forman la base para elaborar diversas medidas estadísticas conocidas como descriptores de Haralick.

\section{Extracción de las Características}

Para cada imagen del patrón de rugosidad, son producidas matrices de co-ocurrencia, considerando en principio una reducción de los niveles de gris para 16 tonos. Las matrices son obtenidas para las direcciones $0^{\circ}, 45^{\circ}, 90^{\circ}$ y $135^{\circ}$ y para distancias $1,2,3,4$ y 5 totalizando de esta forma un conjunto de 20 matrices de dimensión 16x16 para cada imagen. En seguida para cada matriz de co-ocurrencia, se calculan los descriptores de Haralick. Para cada imagen, los valores de los descriptores obtenidos son almacenados en una matriz donde las líneas representan las direcciones y las columnas los valores de los descriptores. La implementación de la metodología de extracción de las características de los patrones considera el diagrama presentado en la Fig. 3.

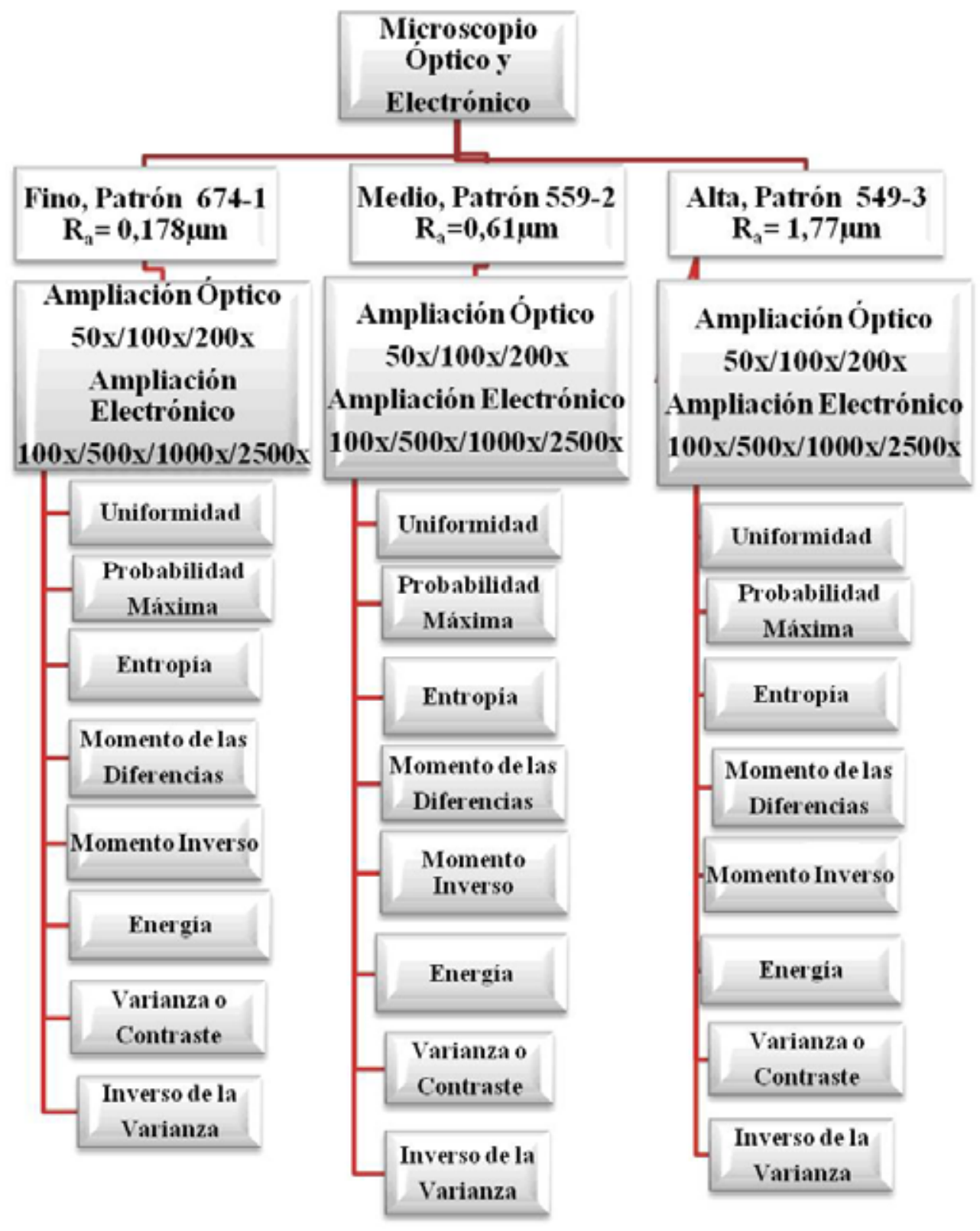

Fig. 3: Diagrama de implementación 


\section{MODELADO DE LA RED NEURONAL ARTIFICIAL}

El modelo de Red Neuronal utilizado en este trabajo es el Perceptron de Múltiples Capas, el cual también fue utilizado en (Lee et al, 2004), donde se presenta un sistema de medición de la rugosidad superficial de piezas torneadas a través de un sistema de visión computacional usando una red neural para esta aplicación. Adicionalmente, este artículo presenta una comparación de redes neurales similar a la realizada por (Mendes et al, 2010), donde a través de las informaciones de sus variables de entrada se busca una mejor arquitectura del modelo neural.

En este modelo, para que sea posible identificar correctamente las entradas que son significativas es necesario que la red neuronal haya sido debidamente entrenada con un conjunto suficiente de patrones que representen un comportamiento satisfactorio y consecuentemente, reconociendo el patrón que está siendo entrenado (Haykin, 2001). Una Red Neuronal Artificial es compuesta, conceptualmente, por una o más capas de neuronas artificiales, que son modelos matemáticos que buscan simular el comportamiento de neuronas biológicas. Semejante a las neuronas biológicas, cada neurona artificial en el modelo posee varias señales de entrada (dendritas), ponderadas por pesos (fuerza de la sinapsis) y apenas una salida (axones). Esta salida es activada si la sumatoria de las entradas ponderadas es mayor o igual a un valor pre-establecido. Los pesos de las entradas conjuntamente con un valor pre-establecido de activación componen el conjunto de valores que son aprendidos por las neuronas a lo largo del entrenamiento (en el caso de neuronas biológicas, a partir de estímulos del ambiente).

En general, en arquitecturas de redes neuronales artificiales del tipo feedforward todas las neuronas de una capa de la red reciben como entradas todas las salidas de la capa anterior (si no es el caso, se puede simplemente fijar pesos nulos para las entradas indeseadas). Las entradas de la primera capa de una RNA están directamente conectadas a las dimensiones de los datos de entrada y las salidas de la última capa representan directamente las dimensiones de los datos de salida. De esta manera, se puede decir que una RNA funciona como una función matemática de $\mathrm{R}^{\mathrm{n}}$ en $\mathrm{R}^{\mathrm{m}}$, siendo $\mathrm{n}$ el número de dimensiones de entrada y $\mathrm{m}$ el número de dimensiones de salida como en la Fig. 4.

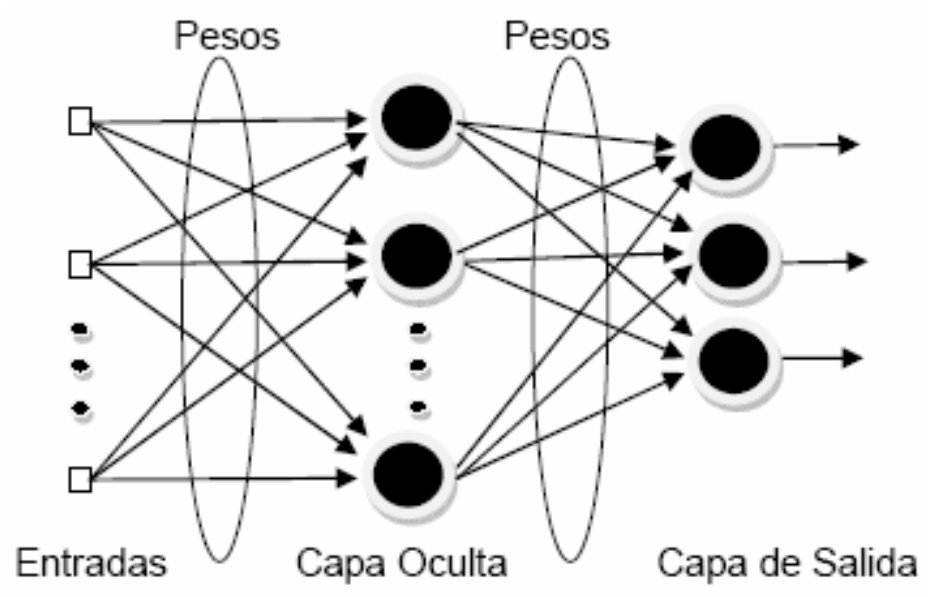

Fig. 4: Arquitectura de una Red Neuronal MLP

A través de técnicas de persistencia se puede almacenar el conocimiento obtenido durante el entrenamiento en un archivo de pesos, a fin de utilizar el mismo conocimiento en el futuro sin que sea necesario realizar nuevamente el entrenamiento. Después que la red neuronal ha sido entrenada, ésta está apta para realizar cuantas clasificaciones sean necesarias, utilizando el conocimiento adquirido para inferir sobre situaciones reales de análisis. La aplicación directa de los descriptores sobre una imagen obtenida del patrón produciría apenas una muestra correspondiente a cada clase de rugosidad, perjudicando la generalidad de las muestras de entrenamiento. Siendo así, fueron evaluadas partes menores de cada patrón de rugosidad posibilitando representar mejor todas las características del patrón examinado. Cada imagen fue, 
por lo tanto dividida en 16 partes. La Fig. 5 presenta la división de una imagen obtenida del microscopio en 16 partes en las cuales los descriptores fueron aplicados.

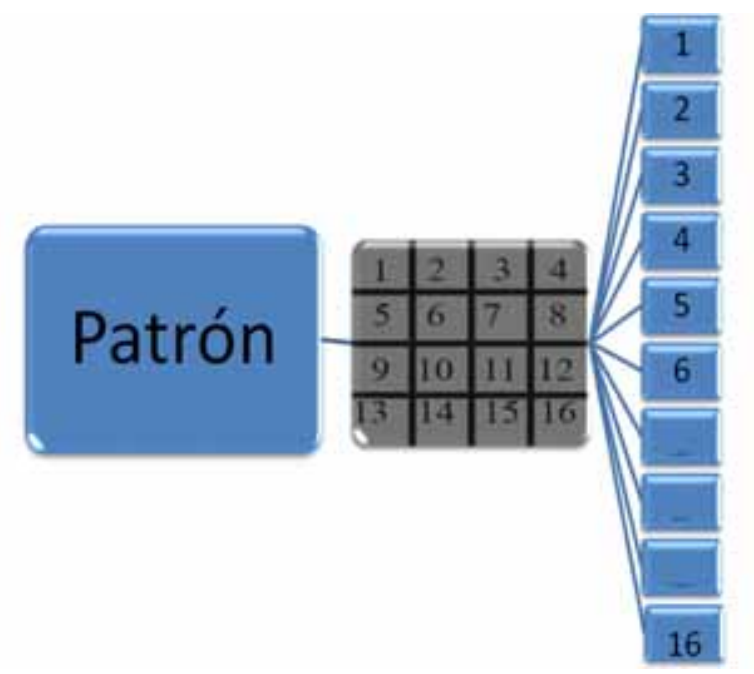

Fig. 5: Subdivisión de la imagen para entrenamiento de la RNA.

Es importante observar que la misma metodología debe ser utilizada para posterior presentación de nuevas imágenes al sistema entrenado. O sea, se puede presentar una región de la imagen seleccionada por ser de mejor calidad; o presentar 16 partes, como en el entrenamiento, para obtener una mejor confiabilidad en la respuesta final, basada en la mayoría de las respuestas para todas las partes evaluadas.

Se nota, entonces, que una RNA tendrá en su última capa tantas neuronas cuanto sean las dimensiones de salida, ya que cada neurona posee apenas una salida. Puede existir una red de una única capa, con tantas neuronas como salidas, mas en general estas redes tienen una capacidad de aprendizaje demasiado limitada para la mayoría de los problemas. Por otro lado, redes de más de una capa como el MLP adicionan nuevos factores a ser adaptados en el proceso de definición de la arquitectura de la red como la cantidad de capas intermediarias y la cantidad de neuronas en estas capas. Se sabe que una red MLP con dos capas ocultas (y una cantidad suficientemente grande de neuronas) es capaz de aproximar adecuadamente cualquier función y que una capa oculta es suficiente para resolver cualquier problema de clasificación como el presentado en este trabajo.

A partir de estas consideraciones, a lo largo de los experimentos fueron definidas las cantidades de neuronas ocultas adecuadas para cada conjunto de muestras presentadas en los resultados. Los conjuntos de datos donde las clases de las muestras están mejor definidas en el espacio, necesitaron de menos neuronas por ser reconocidas más fácilmente. Debido a que el problema está compuesto de tres patrones, para cada patrón de rugosidad, (y considerando cada nivel de aumento del microscopio óptico y electrónico), inicialmente se utilizó apenas una RNA para clasificar las imágenes considerando todos los niveles de aumento del microscopio óptico y electrónico, y posteriormente una red diferente para cada valor de estos aumentos.

Se decidió finalmente por la utilización y entrenamiento de una red separadamente para cada nivel de aumento debido a los resultados significativamente mejores obtenidos. La función de un valor pre-establecido, utilizada en cada neurona para controlar la obtención de la señal de salida se llama función de propagación. En general funciones de este tipo tienden a producir un valor próximo de 0 o -1 para una entrada negativa, y un valor próximo de 1 para una entrada positiva, funcionando como clasificadores simples.

En el caso del MLP, como el algoritmo de entrenamiento (Backpropagation) recorre la superficie del error de la red utilizando un gradiente descendente, es necesario que la función de propagación utilizada sea continua y diferenciable. Las funciones de propagación comúnmente 
utilizadas con el MLP son la Sigmoidal y la Log-Sigmoidal, siendo que la primera retorna valores entre 0 (entrada negativa) y 1 (entrada positiva) y la segunda retorna valores entre - 1 (entrada negativa) y +1 (entrada positiva). Puede decirse que la Log-Sigmoidal posee una salida binaria $(0,1)$ y la Sigmoidal, una salida bipolar $(-1,+1)$. Ambas pueden ser utilizadas con resultados próximos, de manera que después de algunos testes fue decidido que la Sigmoidal sería más adecuada al trabajo en cuestión, por los resultados positivos alcanzados por esa función. Las dos funciones son descritas a continuación:

$$
\begin{aligned}
& \text { Sigmoidal }=\frac{2}{(1+\exp (-2 n))-1} \\
& \text { Log }- \text { Sigmoidal }=\frac{1}{(1+\exp (-n))}
\end{aligned}
$$

En el caso de problemas de clasificación, como este, se acostumbra definir una salida de dimensión para cada clase objetivo, entrenando la red para salidas que tengan valor +1 en la clase correcta de aquella muestra y -1 en todas las otras. Por ejemplo, si hubiese tres clases diferentes, las salidas objetivo serían $(+1,-1,-1),(-1,+1,-1)$ y $(-1,-1,+1)$, respectivamente para la primera, segunda y tercera clases. De esta forma, como en este problema existen tres clases diferentes (correspondiendo a los 3 niveles de rugosidad), la red neuronal utilizada posee por lo tanto, tres dimensiones de salida.

Las muestras conocidas, posteriormente utilizadas en el proceso de entrenamiento, fueron organizadas en una matriz para cada conjunto (determinado por el tipo de microscopio y nivel de aumento), siendo que las columnas representan las diferentes muestras y las líneas, las dimensiones de los datos. Cada dimensión es determinada por una combinación (tipo de descriptor, radio, ángulo), conforme descrito anteriormente para obtención de los valores de los descriptores. La Tabla 3 ilustra la organización de esta matriz.

Tabla 3: Almacenamiento de los resultados de las características

\begin{tabular}{|c|c|c|c|c|}
\hline & Muestra 1 & Muestra 2 & Muestra 3 & Muestra n \\
\hline $\begin{array}{c}\text { Contraste } \\
\text { (radio1, ángulo1) }\end{array}$ & 0,34 & 0,3774 & 0,3791 & 0,3508 \\
\hline $\begin{array}{c}\text { Homogeneidad } \\
\text { (radio1, ángulo1) }\end{array}$ & 4,2762 & 4,12 & 4,85 & 4,65 \\
\hline $\begin{array}{c}\text { Probabilidad Máxima } \\
\text { (radio3, ángulo4) }\end{array}$ & 0,11 & 0,12 & 0,53 & 0,64 \\
\hline
\end{tabular}

Como el número original de entradas del problema, después de aplicados los descriptores, era demasiado grande (cantidad de descriptores vs cantidad de radios vs cantidad de ángulos $=96$ ), y como fue observado que había alguna redundancia en los datos, fue aplicado un preprocesamiento en los datos de entrenamiento. Para tal, se utilizó la PCA (Principal Component Analysis) que consiste en una técnica de análisis de covarianza y reducción de dimensionalidad que transforma linealmente un conjunto de muestras en un nuevo espacio dimensional donde las dimensiones son más representativas cuanto a las relaciones entre los datos. Estas nuevas dimensiones son los auto-vectores de la matriz de covarianza de los datos originales, cuando los auto-valores correspondientes son proporcionales a la varianza en aquella dimensión (Jolliffe, 2002). 
Haciendo esto, es posible descubrir que algunas de las nuevas dimensiones tienen poca varianza, comparadas con las otras, y con eso se pueden descartar las características de varianza más baja, reduciendo de esta manera la dimensionalidad del problema $y$, consecuentemente, su complejidad.

Para este caso fue definido que serían mantenidas las dimensiones cuya contribución relativa fuese mayor o igual a 0.001 . De esta forma se redujo el número de dimensiones en los datos para los valores mostrados en la Tabla 3. Debido a que cada uno posee una distribución diferente, la cantidad de dimensiones con la contribución relativa anterior del a un valor pre-establecido definido varía entre los conjuntos como mostrado en la Fig.6 para el Microscopio óptico y en la Fig.7 para el Microscopio electrónico.

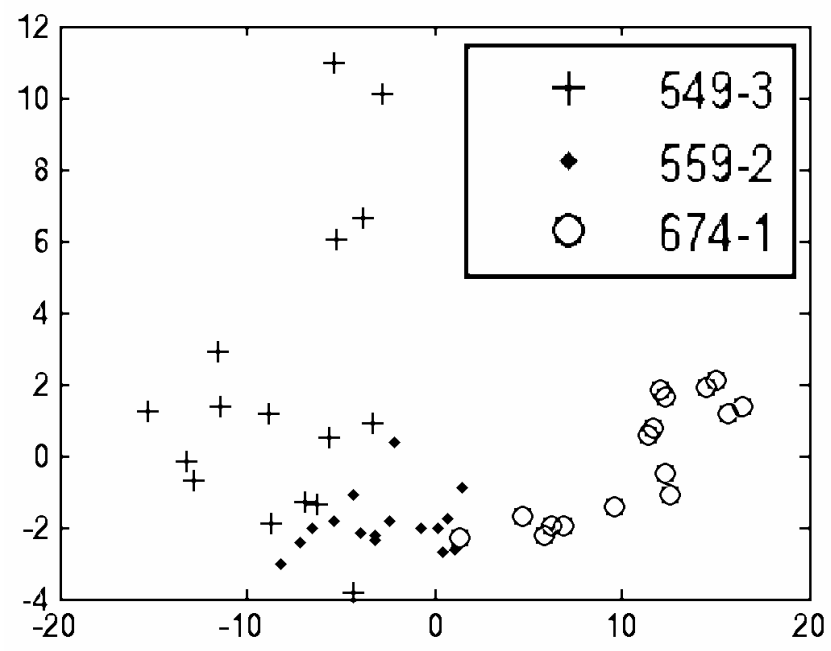

Fig. 6: Conjunto de muestras con las dos dimensiones más significativas, según el PCA, considerando las tres clases de rugosidad $(549,3 ; 559,2$ e 674,1) para el Microscopio óptico

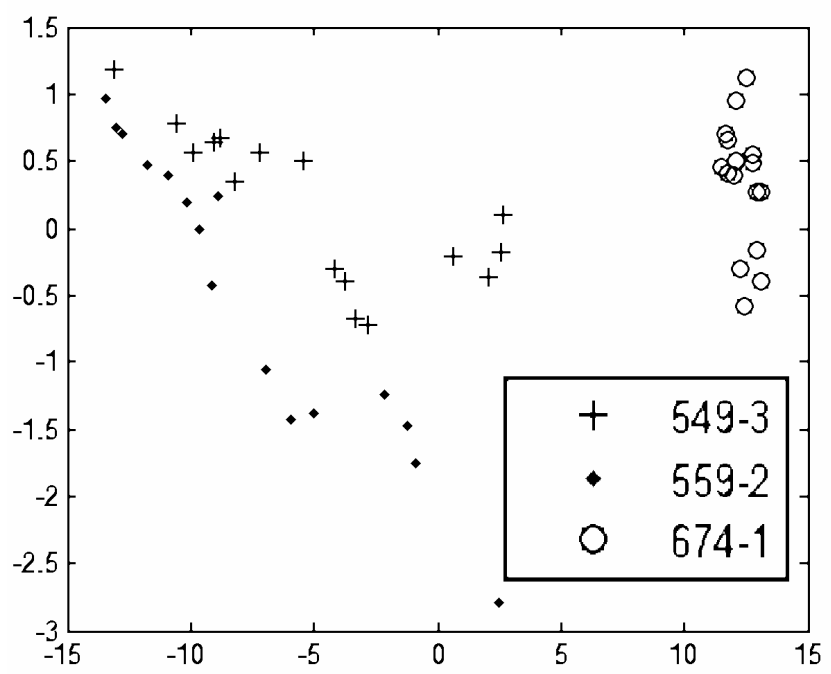

Fig. 7: Conjunto de muestras con las dos dimensiones más significativas, según el PCA, considerando las tres clases de rugosidad $(549,3 ; 559,2$ e 674,1$)$ para el Microscopio electrónico (MEV).

Además, fue aplicado al conjunto de muestras la normalización Z-Score, que consiste en hacer que la población tenga promedio cero y desviación estándar uno; esto es realizado substrayendo el promedio de todas las dimensiones de los puntos y subsecuentemente dividiéndolos por el desviación estándar. Los valores del promedio y desviación estándar obtenidos en el momento del entrenamiento deben ser usados también para normalizar nuevas muestras posteriormente, de modo que la red sea entrenada para trabajar con los conjuntos normalizados usando los valores originales. 


\section{ENTRENAMIENTO DE LA RNA}

El proceso de entrenamiento de la red MLP utiliza el algoritmo Backpropagation, que consiste en modificar el conjunto de pesos de la red de manera a reducir el error de las salidas obtenidas en relación a las esperadas. Para conseguir esto, después de una inicialización aleatoria de los pesos, son ejecutados varios pasos que consisten en: 1 - presentar todo el conjunto de entradas utilizado para el entrenamiento a la red; 2 - verificar la salida que ésta produjo; 3 - comparar con las salidas esperadas para tales muestras (previamente conocidas); y 4 - adaptar los pesos de la red de modo que este error disminuya en el próximo paso.

La adaptación de los pesos se efectúa siguiendo la misma dirección pero el sentido opuesto del vector gradiente en la superficie del error en función de los pesos. Durante el entrenamiento, se separa el conjunto de muestras conocidas en tres conjuntos: entrenamiento, validación y teste. Las muestras de entrenamiento son efectivamente presentadas a la red y tienen sus salidas comparadas con las esperadas para el ajuste de pesos. Las muestras de validación son presentadas a la red después de cada ciclo de entrenamiento y si el error para este conjunto sube más que un número predeterminado de ciclos con relación al ciclo anterior, el entrenamiento es interrumpido. Este método es utilizado para garantizar que la red no pierda generalización.

Se puede observar en las Figuras 8 a 14 la evolución del error en los tres conjuntos de muestras (entrenamiento, validación y teste) para cada nivel de aumento, el error en el conjunto de teste, considerado al final del entrenamiento, es utilizado para comparar el resultado de entrenamientos diferentes y escoger el mejor ente ellos. La disminución del error es mayor para el conjunto de entrenamiento porque el proceso de entrenamiento se realiza con el propósito de disminuir directamente este valor, cuando la disminución en los otros conjuntos (no utilizados en el ajuste de pesos) es un indicador de la generalización de la red. Es importante observar que la escala del eje vertical es logarítmica, o sea, una disminución lineal en la línea del gráfico en realidad corresponde a una disminución exponencial en el valor del error. Se observa que las Figuras 8 , 10, 12 y 13 poseen una convergencia muy buena, consecuentemente resultará en un excelente análisis de valores y resultará en un porcentaje mayor de aciertos que el presentado en las Figuras 9, 11 y 14.

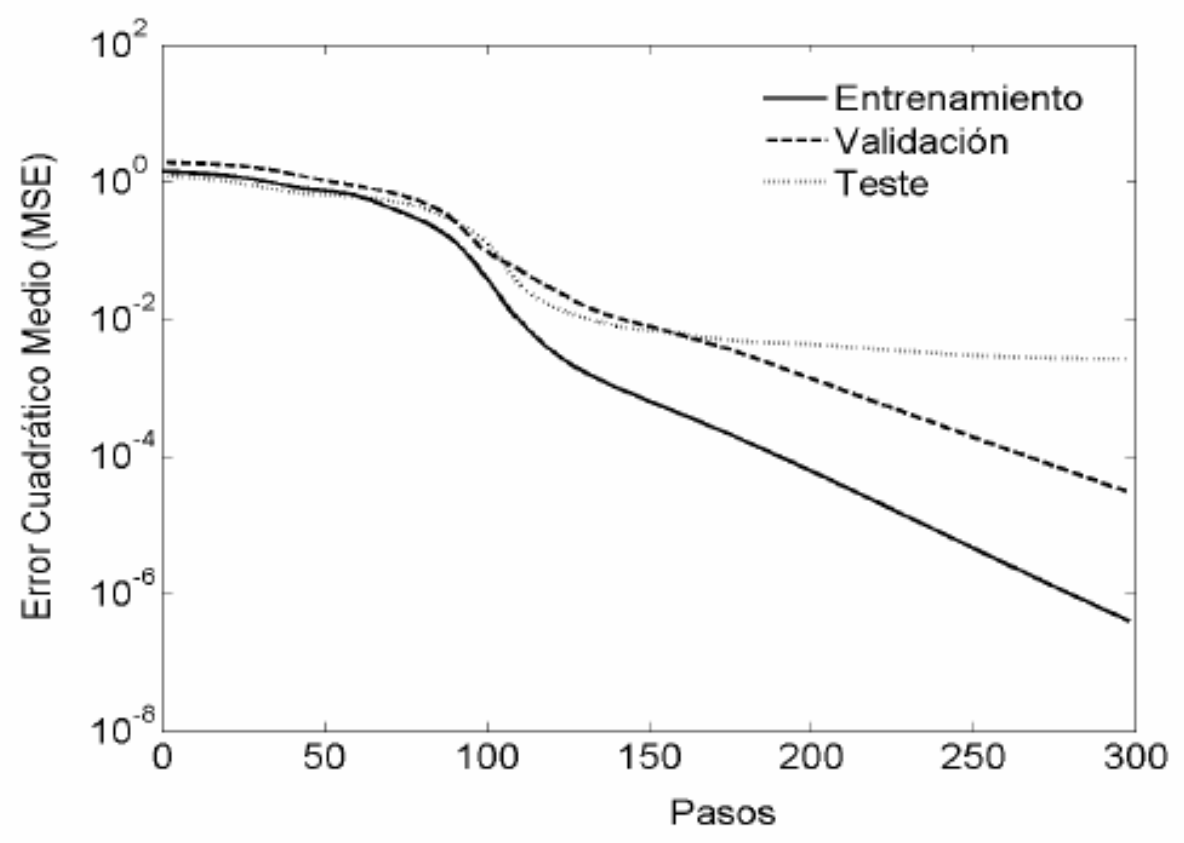

Fig. 8: Evolución del error en el conjunto de aumento 50 veces para el Microscopio óptico. 


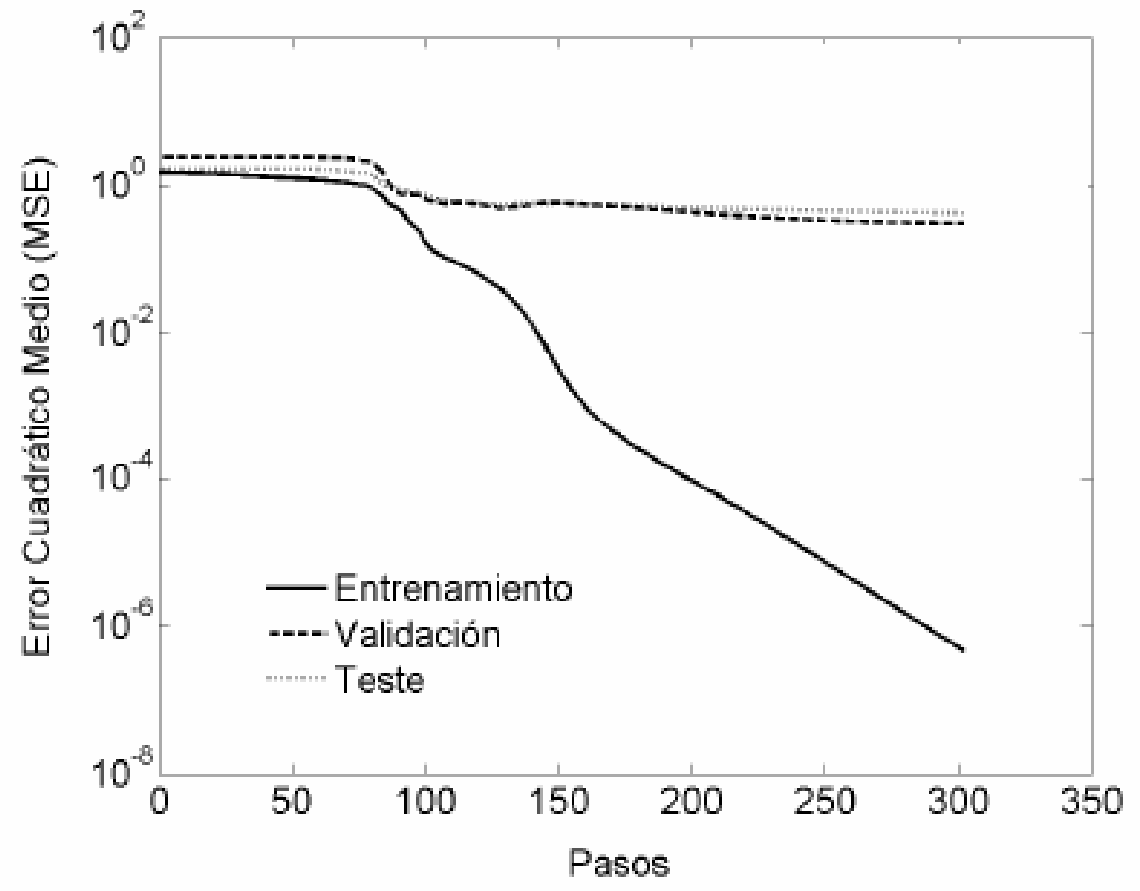

Fig. 9: Evolución del error en el conjunto de aumento 100 veces para el Microscopio óptico

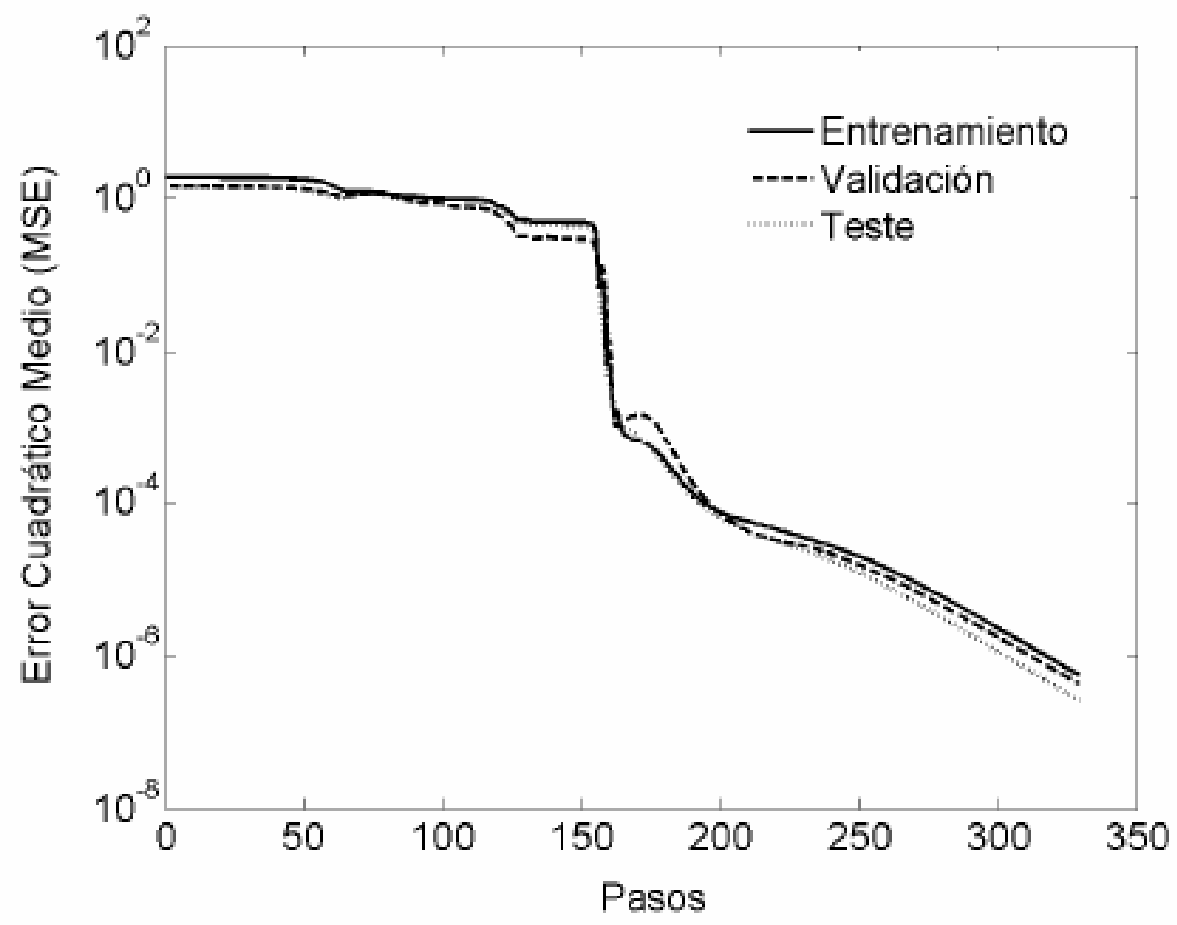

Fig. 10: Evolución del error en el conjunto de aumento 200 veces para el Microscopio óptico. 


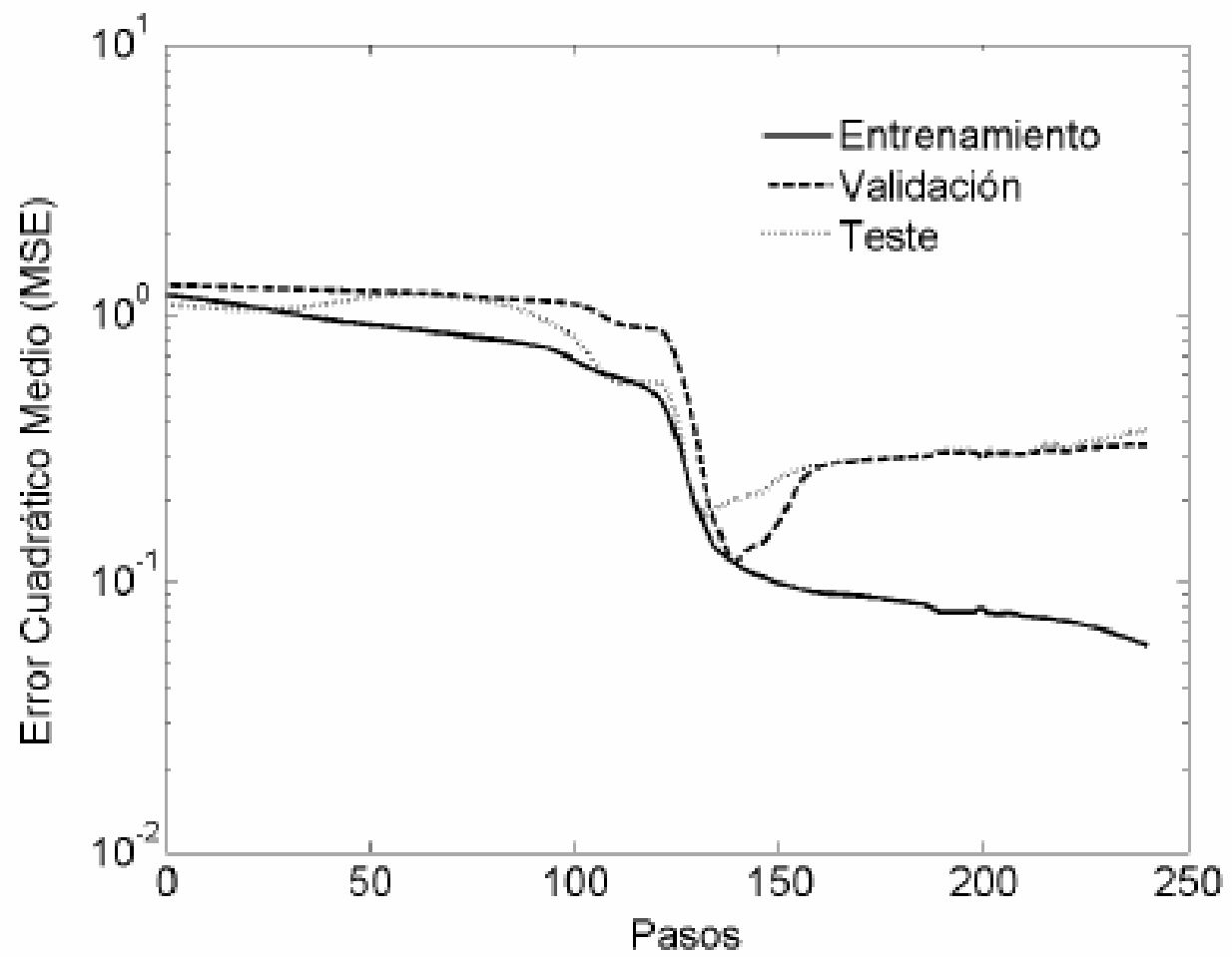

Fig. 11: Evolución del error en el conjunto de aumento 100 veces para el Microscopio electrónico (MEV).

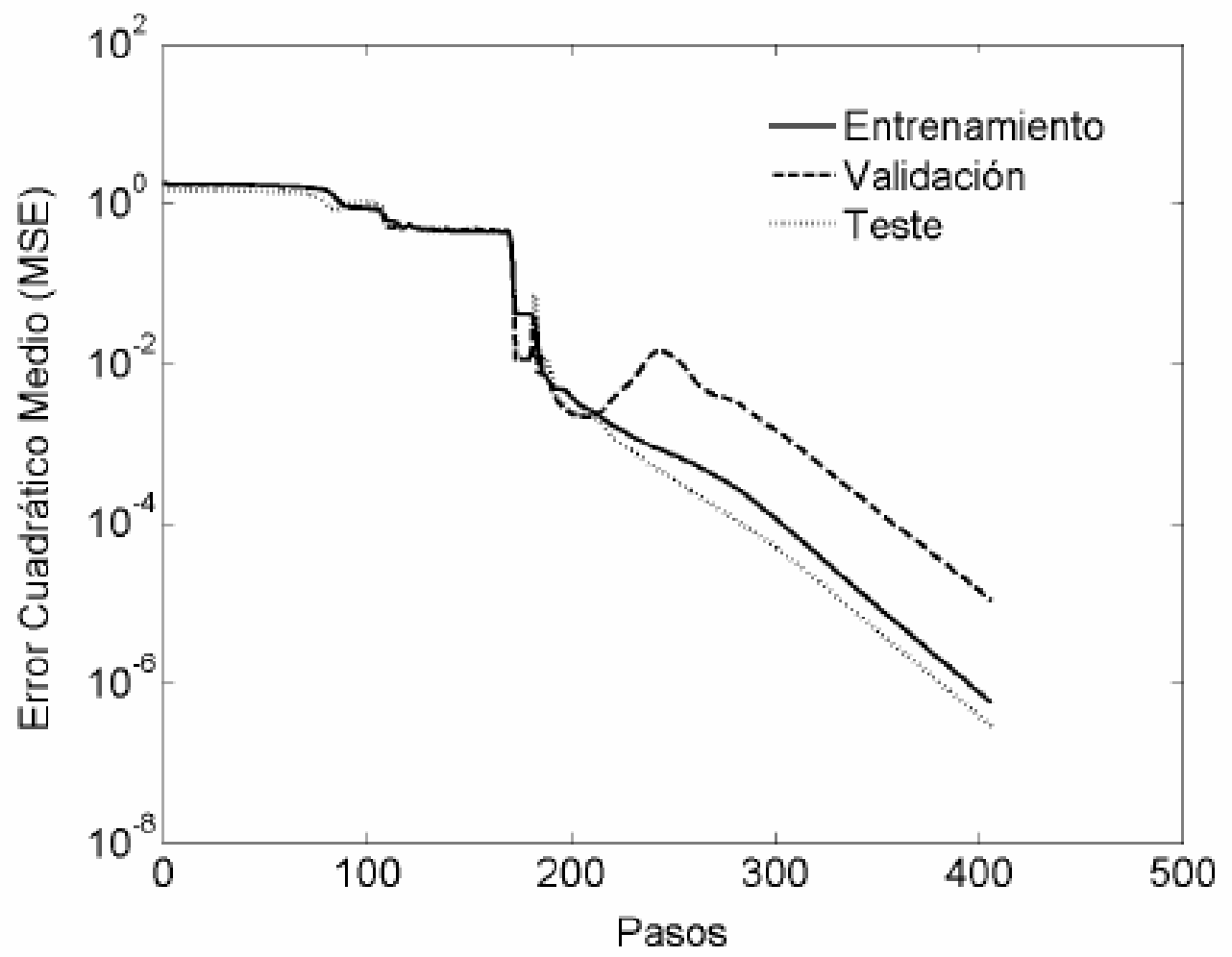

Fig. 12: Evolución del error en el conjunto de aumento 500 veces para el Microscopio electrónico (MEV). 


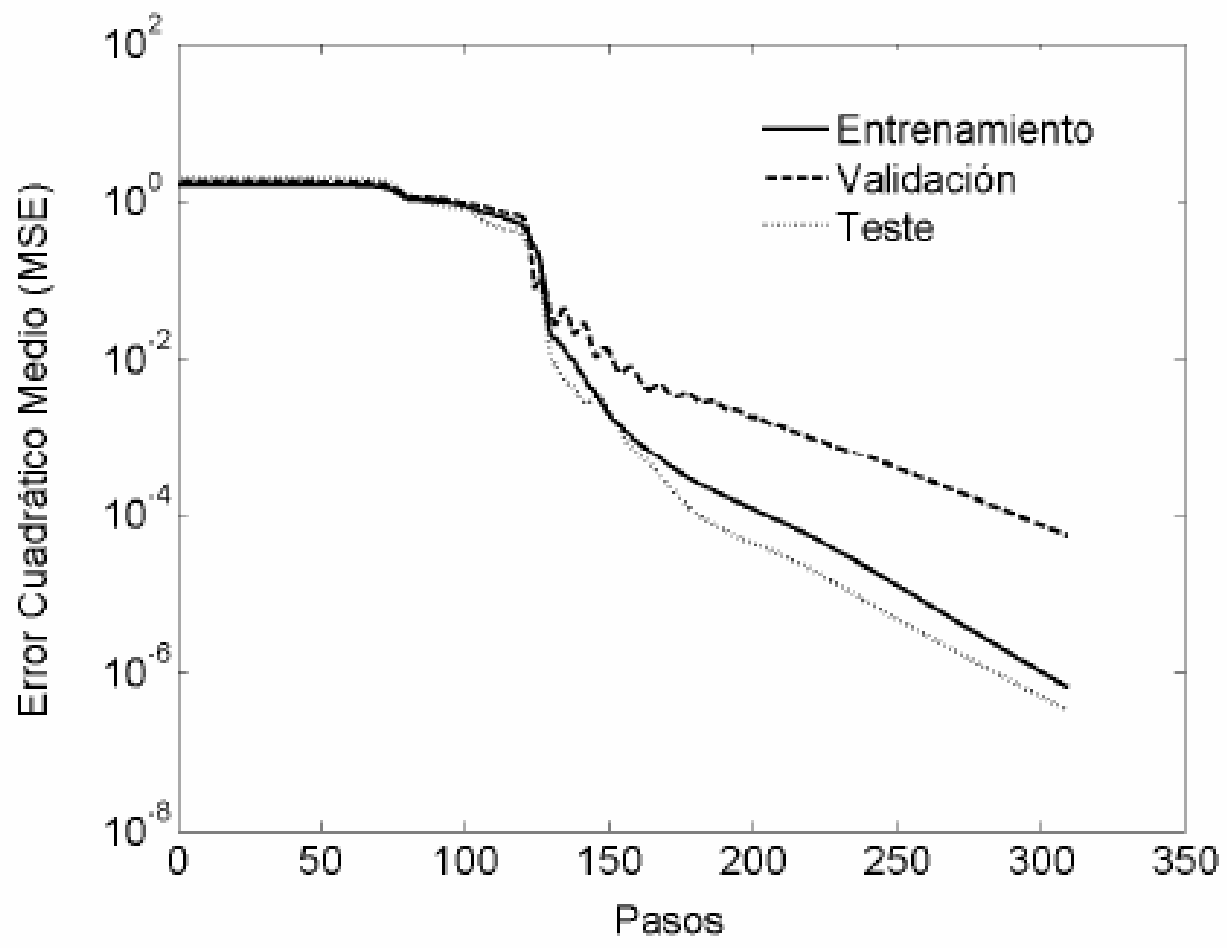

Fig. 13: Evolución del error en el conjunto de aumento 1000 veces para el Microscopio electrónico (MEV).

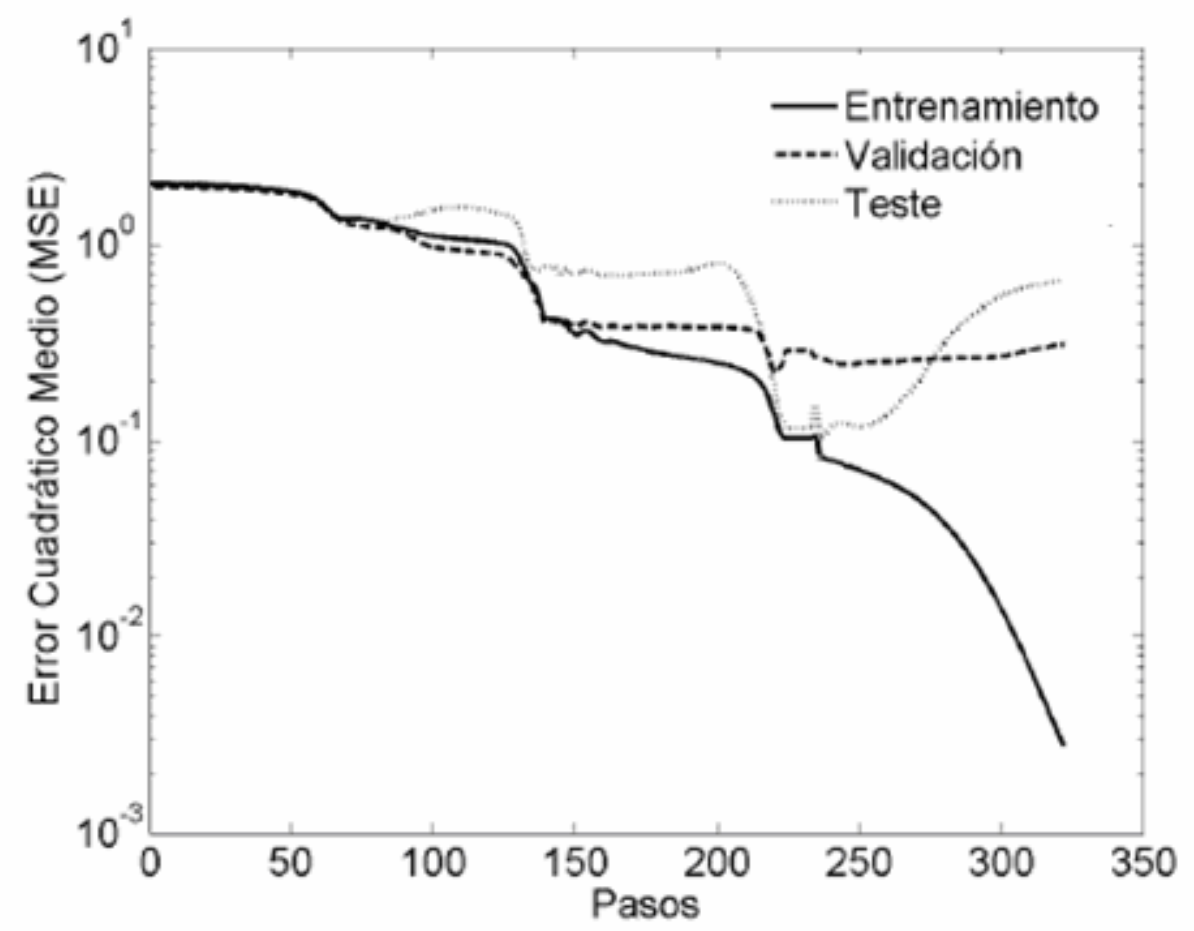

Fig. 14: Evolución del error en el conjunto de aumento 2500 veces para el Microscopio electrónico (MEV). 
Es relevante resaltar que el codominio de las funciones de propagación del MLP es abierto en los extremos, porque estas funciones son asintóticas, alcanzando los extremos apenas en el límite cuando el argumento tiende a infinito. Esto hace con que las salidas producidas por una red MLP nunca sean exactamente iguales a las deseadas (a pesar de estar muy próximas), lo que implica que el error del entrenamiento nunca podrá alcanzar un cero absoluto. Considerando los valores de $\mathrm{Ra}$ como los parámetros después del procesamiento, se definió la primera clase $(+1,-1,-1)$ como la muestra $674-1$; la segunda $(-1,+1,-1)$ como el material $559-2$ y la tercera $(-1,-1,+1)$ como el material 549-3. Así, la salida de la red neuronal (en la forma de las tres dimensiones en el dominio real $(-1,+1)$ es convertida a un único valor real, representando la rugosidad $\mathrm{Ra}$ del material identificado, o cero en caso de incertidumbre, definido como un caso donde ninguna de las dimensiones de salida, o más de una, tiene valor mayor que +0.8 .

\section{RESULTADOS}

La Tabla 4 y 5 presentan la arquitectura final de las Redes Neuronales entrenadas y sus respectivas tasas de acierto para cada nivel de zoom de los Microscopios óptico y electrónico (MEV).

Tabla 4: Configuración final de las Redes y tasas de error para el Microscopio óptico.

\begin{tabular}{|c|c|c|c|}
\hline Nivel de Aumento & Cantidad de Neuronas Ocultas & $\begin{array}{c}\text { Dimensiones de Entrada } \\
\text { Después del PCA }\end{array}$ & $\%$ de Acierto \\
\hline 50 veces & 5 & 10 & 100 \\
\hline 100 veces & 8 & 10 & 95,8 \\
\hline 200 veces & 2 & 7 & 100 \\
\hline
\end{tabular}

Tabla 5 : Configuración final de las Redes y tasas de error para el Microscopio electrónico (MEV).

\begin{tabular}{|c|c|c|c|}
\hline Nivel de Aumento & $\begin{array}{c}\text { Cantidad de Neuronas } \\
\text { Ocultas }\end{array}$ & $\begin{array}{c}\text { Dimensiones de Entrada } \\
\text { Después del PCA }\end{array}$ & $\%$ de Acierto \\
\hline Mev 100 veces & $2-8$ & 5 & 89,5 \\
\hline Mev 500 veces & 2 & 4 & 100 \\
\hline Mev 1000 veces & 2 & 4 & 100 \\
\hline Mev 2500 veces & $2-8$ & 5 & 87,5 \\
\hline
\end{tabular}

Se puede percibir en la Tabla 4 que las imágenes con mayor nivel de aumento (200 veces) se mostraron más adecuadas para la utilización en el sistema propuesto. Se puede deducir que las relaciones entre muestras para este caso son las más representativas de sus respectivas clases de rugosidad y con redundancia bien definida.

Al mismo tiempo, cuando la menor aumento (50 veces) se mostró adecuadamente viable, a pesar de ser necesario un entrenamiento y ajuste de parámetros más complejo, las imágenes da aumento media (100 veces) se mostraron como las peores entre las estudiadas, no siendo recomendables para una implementación final del sistema. Se puede entonces observar a través de la Tabla 5 que las imágenes con aumento (500 veces e 1000 veces) probaron ser las más adecuadas para utilización del sistema propuesto. Adicionalmente las relaciones entre las muestras son más parecidas a sus respectivas rugosidades. De la misma manera, las ampliaciones de otros (100 veces y 2500 veces) fueron no satisfactorias, entre los estudiados, no siendo recomendado para una aplicación final del sistema. 
Se puede concluir también, que existe una relación directa entre los parámetros aplicados para obtención de los valores de los descriptores de Haralick y el mejor nivel de aumento de las imágenes de origen, de modo que haya la mejor correspondencia posible entre las distancias en el modelo de Haralick (medidas en pixeles) y las distancias entre las micro-características del material analizado. Adicionalmente, el propio proceso de entrenamiento ya ejecuta testes de generalización con las muestras dentro de las clases consideradas.

Siendo así, después del entrenamiento, fueron realizados testes con muestras de una clase diferente a las tres consideradas, y que nunca fueron presentadas a la red durante el entrenamiento. Conforme esperado, la salida final del sistema fue un valor de cero para la rugosidad del material, indicando desconocimiento de las muestras. Finalizando, concluyendo que por los datos presentados dentro de las configuraciones finales de las redes y la tasa de error presentada que las imágenes del microscopio óptico tuvieron un porcentaje de acierto mayor.

\section{CONCLUSIONES}

El aporte de este estudio se traduce en la posibilidad de evaluar la rugosidad superficial a través de una imagen. Para esto, fue desarrollada la configuración de un sistema de descriptores de Haralick que alimentaron una red neuronal que facilita el reconocimiento de la rugosidad superficial en patrones de rugosidad de bajos valores. Este sistema comparó los resultados numéricos de imágenes obtenidas con diferentes tipos de microscopios óptico y electrónico, en diferentes escalas y con varias configuraciones de rede neurales, para alcanzar un sistema con el mayor porcentaje de acierto posible.

Al analizar todos los resultados y variables, se observó que los valores más satisfactorios para a implementación del sistema son los obtenidos del microscopio óptico con aumento de 200 veces. Adicionalmente, concluimos que la implementación del control de piezas para inspección de la calidad industrial de productos manufacturados es económicamente factible a partir de este sistema de reconocimiento de rugosidad debido al costo inferior del microscopio óptico.

\section{AGRADECIMENTOS}

Los autores agradecen al Dr. Juan Carlos Mateus Sánchez por sus valiosos comentarios y sugerencias en la redacción de este artículo, a FAPERJ por el apoyo financiero (No E26/171.362/2001).

\section{REFERENCIAS}

Alegre, E., Alaiz-Rodríguez, R., Barreiro, J., Fidalgo E., Fernández, L.; Surface Finish Control in Machining Processes Using Haralick Descriptors and Neuronal Networks, Computational Modeling of Objects Represented in Images Lecture Notes in Computer Science, Volume 6026/2010, 231241 (2010).

Bashar, M. K. Tsumoto, T. M. y Ohnishi, N. ; Wavelet Transform-Based Locally Orderless Images For Texture Segmentation, Pattern Recognition Letters, V. 24, N. 15, Pages 2633-2650 (2003).

Bongaerts, J. H. H., Foutouni, K., Sotokes, J. R.; Soft-tribology: Lubrication in a compliant PDMSPDMS contact. Tribology International, Vol. 40, pp. 1531-1542, (2007).

Ginneken, B. van, Romeny, B. M. ter H.; Multi-scale texture classification from generalized locally ordeless images, Pattern Recognition 36, pages 899-911 (2003).

Haralick, R. M.; Shanmugan, K. y Dinstein; Texture Features For Image Classification, IEEE Transaction on Systems, Man and Cybernetics (Smc-3), V.6, N. 3, Pages.610-621 (1973).

Haralick, R. M.; Statistical and Structural Approaches to Texture, Proceedings of The IEEE, v.67, n. 5, Pages 786-804 (1979).

Harasaki, A., Schmit, J., Wyant ,J. C.; Improved vertical-scanning interferometry. Appl Opt 39:2107-2115 (2000). 
Haykin, S.; Neural Networks:A Comprehensive Foundation, Prentice Hall, (1999).

Hocken, R. J.; Chakraborty, N., Brown, C.; Optical metrology of surfaces. Ann CIRP 54(2):705-719 (2005).

ISO 25178-6, Geometrical product specifications (GPS) - Surface texture: areal, classification of methods for measuring surface, texture International Organization for Standardization Committee, (2010).

ISO 4287, Geometrical product specifications (GPS) - Surface texture: profile method-terms, definitions and surface texture parameters, International Organization for Standardization, Geneva, Switzerland, (1997).

Jolliffe, I. T.; Principal Component Analysis: Springer, Second Edition, 2nd ed., XXIX, 487 p. 28 illus., Hardcover (2002).

Lee, B. Y., Yu, S. F., Juan, H.; The model of surface roughness inspection by vision system in turning, Mecatronics14:129-141 (2004).

Markou, M.; Singh, S.; Novelty detection: a review(part 1): statistical approaches, Department of Computer Science, PANN Research, University of Exeter, Signal Processing 83, Pages 2481-2497 (2003).

Mendes, V. B., Leta, F. R., Conci, A. y Gonçalves; L. B.; Detección de Posición Angular de Embarcaciones, utilizando Técnicas de Visión Computacional y Redes Neurales Artificiales, Inf. tecnol., vol.21, no.6, p.177-188 (2010).

Oktem, H., Erzurumlu, T. y Kutaran, H.; Applications of response surface methodology in the optimization of cutting conditions for surface roughness, Journal of Materials Processing Technology 170:11-1 (2005).

Ozcelik, B., Bayramoglu, M.; The statistical modeling of surface roughness in high-speed flat end milling, International Journal of Machine Tool \& Manufacture, Vol.46, pp. 1395-1402 (2006).

Paschos, G.; Petrou, M.; Histogram ratio features for color texture classification, Pattern Recognition Letters, v. 24, n. 1-3, Pages. 309-314, (2003).

Prakasvudhisarn, C., Kunnapapdeelert, S., Yenradee, P.; Optimal cutting condition determination for desired surface roughness in end milling, The International Journal of Advanced Manufacturing Technology, 41:440-451 (2009).

Reddy, N. S. K., Rao, P. V.; Selection of optimum geometry and cutting conditions using surface roughness prediction model for end milling, The International Journal of Advanced Manufacturing Technology, 26:1202-1210 (2005).

Rhee, H. G., Vorburger, T. V., Lee, J. W., Fu, J.; Discrepancies between roughness measurements obtained with phase-shifting interferometry and white-light interferometry. Appl Opt 44:5919-5927 (2005).

Sengur, A.; Turkoglu, I., y Ince, M. C.; Wavelet packet neural networks for texture classification, Expert Systems with Applications Volume 32, Issue 2, February, Pages 527-533 (2007).

Varma, M., Zisserman, A.; A statistical approach to texture classification from single images, International Journal of Computer Vision 62 , Pages 61-81 (2005).

Vorburger, T. V., Rhee, H. G., Renegar, T. B., Song, J. F., Zheng, A.; Comparison of optical and stylus methods for measurement of surface texture, The International Journal of Advanced Manufacturing Technology, 33:110-118 (2007).

Yang, X. y Liu, J.; Maximum entropy random fields for texture analysis, Pattern Recognition Letters, v. 23, n. 1-3, pages 93-101 (2002).

Zain, A. M., Haron, H., Sharif, S.; Application of GA to optmize cutting conditions for minimizing surface roughness in end milling machining process. Expert Systems and Applications. Vol. 37, pp. 4650-4659 (2010). 